\title{
A Model for Turbulent Diffusion in a Vertically Inhomogeneous Atmospheric Boundary Layer
}

\author{
Moreira, D. M.;* Tirabassi, T.; Guarieiro, L. L. N.; Moret, M.
}

Rev. Virtual Quim., 2016, 8 (4), 1220-1233. Data de publicação na Web: 30 de julho de 2016

http://rvq.sbq.org.br

\section{Um Modelo para Difusão Turbulenta em uma Camada Limite Atmosférica Verticalmente não Homogênea}

Resumo: Neste trabalho é apresentada uma solução analítica da equação de difusão turbulenta unidimensional, considerando fechamento não-Fickiano em uma camada limite atmosférica não homogênea. A presente solução é melhorada e mais consistente fisicamente na descrição da dispersão, pois inclui velocidade de queda de partículas grandes, skewness, escala de tempo Lagrangeano vertical e tempo de relaxação (difusão com velocidade finita). Analisamos a influência do termo de contragradiente, deposição seca e velocidade de queda sobre o campo de concentração de poluentes através de simulação numérica. Os resultados demonstram um exemplo da utilidade das soluções analíticas da equação de difusãoadvecção.

Palavras-chave: Contragradiente; difusão turbulenta; Camada limite atmosférica; Velocidade de queda; Deposição.

\begin{abstract}
An analytical solution of the one-dimensional turbulent diffusion equation considering nonFickian closure in a vertically inhomogeneous atmospheric boundary layer (ABL) is presented. The presented solution is improved and more physically consistent in the description of dispersion because it includes (for the first time) the explicit gravitational settling $\left(w_{s}\right)$ of large particles. Moreover, deposition velocity $\left(v_{d}\right)$ as a boundary condition, vertical turbulent velocity $\left(\sigma_{w}\right)$, skewness $\left(S_{k}\right)$, vertical Lagrangian time $\left(T_{L_{w}}\right)$ scale and relaxation time $(\tau)$ ("finite-velocity" diffusion) are included. Via numerical simulations, we analyzed the influence of the countergradient term, dry deposition to the ground and gravitational settling on the concentration field. Our results demonstrate an example of the usefulness of analytical solutions to the advection-diffusion equation.
\end{abstract}

Keywords: Countergradient; Turbulent diffusion; Atmospheric boundary layer; Gravitational settling; Deposition.

* SENAI CIMATEC, Modelagem Computacional, Av. Orlando Gomes, 1845, Piatã, Salvador-BA, Brasil.

M davidson.moreira@fieb.org.br

DOI: $10.21577 / 1984-6835.20160087$

Rev. Virtual Quim. |Vol 8 | |No.4| |1220-1233| 


\section{A Model for Turbulent Diffusion in a Vertically Inhomogeneous Atmospheric Boundary Layer

\author{
Davidson M. Moreira, ${ }^{a, *}$ Tiziano Tirabassi, ${ }^{b}$ Lilian L. N. Guarieiro, ${ }^{a}$ \\ Marcelo Moret $^{a}$
}

a SENAI CIMATEC, Modelagem Computacional, Av. Orlando Gomes, 1845, Piatã, Salvador-BA, Brasil.

${ }^{b}$ Institute ISAC of CNR, Via Gobetti, 101 - I-40129, Bologna, Italy.

* davidson.moreira@fieb.org.br

\section{Introduction \\ 2. The solution \\ 3. Numerical results \\ 4. Conclusions}

\section{Introduction}

Atmospheric pollutant removal using a deposition process is an important part of dispersion and transport because this process can have a significant impact on concentration distributions in the atmospheric boundary layer (ABL). The Earth's surface is a sink for trace gases and particles emitted in the atmosphere or synthesized by chemical reactions. The transfer of gases and particles to the surface occurs via two pathways: wet and dry deposition. The various transfer mechanisms leading to dry deposition are complex and involve micrometeorological characteristics of the atmospheric surface layer, including the atmospheric turbulence intensity, the nature of the gas and particles and the nature of the surface itself. The modeling of air pollution dispersion, including dry deposition, was first attempted by modifying the Gaussian plume equation. ${ }^{1,2}$ These attempts included algorithms that are not strictly related to the phenomenon in the surface depletion models, and many virtual emission sources were introduced. ${ }^{3,4}$ Many solutions also retained the variables of invariant wind speed and eddy diffusivity simplification functions with height. ${ }^{5-7}$ Tsuang ${ }^{8}$ proposed a Gaussian model where the dispersion coefficients ("sigma") are functions of time and height.

The advection-diffusion equation can be written in finite difference form, thus allowing for a variety of numerical solutions. Using the gradient transport approach (Ktheory), dry deposition can be analyzed by specifying the deposition flux as the surface boundary condition. In this paper, we present an exact solution for vertical diffusion describing the flow of particulate matter emitted from tall sources to the ground (with 
settling velocity).

The simplicity of the turbulent diffusion Ktheory has led to its widespread for mathematically simulating pollutant dispersion (open country, urban, photochemical pollution, etc.). However, Kclosure has limitations. A significant problem is that the down-gradient transport hypothesis is inconsistent with observed turbulent diffusion features in the upper portion of the mixed layer, based on convective cases where countergradient material fluxes are known to occur. ${ }^{9}$ Because countergradient fluxes are thought to be indicative of boundary layer scale eddies, as opposed to small scale eddies, such fluxes are often called non-local fluxes. Local K-theory is a method for parameterizing the effects of

$$
\overline{w^{\prime} c^{\prime}}=-K_{z}\left(\frac{\partial c}{\partial z}-\gamma\right)
$$

where $\gamma$ represents the countergradient term; $K_{z}$ von Karman's constant and $\overline{w^{\prime} c^{\prime}}$ is the vertical turbulent concentration flux

Many schemes and parameterizations for the turbulent mixing based on how well small eddies mix quantities along a local gradient of the transported quantity. It has been noted that in the upper part of convectively driven boundary layers, the flux of scalars occur opposite the gradient of the mean scalar profile. ${ }^{10}$ The mean potential temperature gradient and the flux change sign at different levels, creating certain regions in the convective boundary layer where they have the same sign. This contrasts the common view in first order turbulent closure, which suggests that turbulent diffusion occurs down gradient. To describe diffusion in these regions, Deardoff ${ }^{10,11}$ proposed a modification of the usual applied fluxgradient relationship from the K-theory approach according to:

$$
\left[1+\left(\frac{S_{k} T_{L_{w}} \sigma_{w}}{2}\right) \frac{\partial}{\partial z}+\tau \frac{\partial}{\partial t}\right] \overline{w^{\prime} c^{\prime}}=-K_{z} \frac{\partial c}{\partial z}
$$

countergradient term have been developed. ${ }^{12-16}$ In this paper, we utilize the parameterization proposed by van Dop and Verver (eq. 2). ${ }^{17}$

where $S_{k}$ is the skewness of the vertical turbulent velocity (updraft and downdraft regions), $\sigma_{w}$ is the standard deviation of the vertical turbulent velocity, $T_{L_{w}}$ is the vertical Lagrangian time scale and $\tau$ is the relaxation time ("finite-velocity" diffusion). The second term in the operator (in brackets) represents the non-local countergradient term.

In a recent study, ${ }^{18}$ was found a solution to the one-dimensional equation for the case of gravitational settling within a capped boundary layer. This equation describes the diffusion of the horizontally integrated concentration distribution:

$$
\frac{\partial c}{\partial t}-w_{s} \frac{\partial c}{\partial z}=-\frac{\partial \overline{w^{\prime} c^{\prime}}}{\partial z}
$$


where $\mathrm{w}_{\mathrm{s}}$ is the gravitational settling and $\mathrm{c}$ is the average concentration.

However, the solution for this equation was obtained with Fickian closure ( $\overline{w^{\prime} c^{\prime}}=-K_{z} \frac{\partial c}{\partial z}$ ) and assumed vertical eddy diffusivity as a power-law function ( $K_{z}=k u_{*} z$, where $u_{*}$ is the friction velocity and $k$ is von Karman's constant). For most analytic solutions of (Eq. 3), the K-coefficient is assumed to be a power-law function of height. However, a K-coefficient based on a power law is not realistic for the atmospheric boundary layer. ${ }^{19}$ Analytical solutions to the turbulent diffusion equation are well summarized in the work of Pasquill and Smith. ${ }^{20-22}$

In this work, we solve Eq. 3 considering gravitational settling and deposition to the ground with general vertical profiles of eddy coefficients, which are expressed using stepwise functions. The literature does not offer a solution to Eq. 3 for these specific atmospheric and physical conditions. The proposed solution allows for the investigation of more energetic eddies at different heights and the effect of the asymmetric transport in the computation of the pollutant concentration, while considering the turbulent dispersion structure in a more complete manner.

\section{The solution}

First, we must note the work of Moreira. ${ }^{23,24}$ In these studies, they reported a multilayer model with Fickian closure in a steady bidimensional advection-diffusion equation. The model uses the ADMM solution (Advection-Diffusion Multi-layer Method). ${ }^{24}$ This model mainly relies on the following steps: a stepwise approximation of eddy diffusivity and wind speed, a Laplace transform application to the advectiondiffusion equation based on the $t$ variable, a semi-analytical solution of the set of linear ordinary equations resulting from the Laplace transform application and construction of the pollutant concentration via an inverse Laplace transform. Following this methodology, but now with non-Fickian closure in a one-dimensional diffusion equation, we can apply Eq 2 to Eq. 3. To solve the advection-diffusion equation for inhomogeneous turbulence, we must account for the dependence of the eddy diffusivities on height (variable $z$ ). We utilize the ADMM method to perform a stepwise approximation of these coefficients. ${ }^{24}$ To do so, we discretize the height of the $A B L$ into $N$ sub-intervals in such a manner that inside each sub-region the eddy diffusivities assume average values. These yields:

$$
\begin{aligned}
& \frac{\partial c_{n}(z, t)}{\partial t}-\tau \frac{\partial^{2} c_{n}(z, t)}{\partial t^{2}}-w_{s} \frac{\partial c_{n}(z, t)}{\partial z}-w_{s} \beta_{z}^{n} \frac{\partial^{2} c_{n}(z, t)}{\partial z^{2}}-w_{s} \tau \frac{\partial}{\partial t}\left(\frac{\partial c_{n}(z, t)}{\partial z}\right)+ \\
& +\beta_{z}^{n} \frac{\partial}{\partial z}\left(\frac{\partial c_{n}(z, t)}{\partial t}\right)=K_{z}^{n} \frac{\partial^{2} c_{n}(z, t)}{\partial z^{2}}
\end{aligned}
$$

for $0<z<h$ and $t>0$, where $\beta_{z}^{n}=0.5 S_{k} \sigma_{w}(z) T_{L_{w}}(z)$ (in this work $S_{k}$ is constant, but may be a function of $z$ ), $\sigma_{w}$ is the vertical turbulent velocity, $S_{k}$ is the skewness, $T_{L_{w}}$ is the vertical Lagrangian time scale, $\tau$ is the relaxation time, $w_{s}$ is the settling velocity, $c_{n}$ represents the concentration and $K_{z}^{n}$ is the vertical eddy diffusivity (index $n$ indicates that the variables are evaluated in the $\mathrm{n}^{\text {th }}$ layer, which divide the $A B L$ ).

The pollutants are also subjected to the boundary conditions: 
Moreira, D. M. et al.

$$
\begin{gathered}
K_{z} \frac{\partial c}{\partial z}=0 \quad \text { at } z=h \\
\text { and } \\
K_{z} \frac{\partial c}{\partial z}+w_{s} c=v_{d} c \quad \text { at } z=0
\end{gathered}
$$

where $h$ is the ABL height, $v_{d}$ is the total dry deposition velocity (at $z=0$, $K_{z}=K_{0}=$ constant) and $w_{s}$ is the settling velocity. We assumed a constant emission rate source $Q$ (initial condition):

$$
c(z, 0)=Q \delta\left(z-H_{s}\right) \text { at } t=0
$$

where $\delta\left(z-H_{s}\right)$ is the Dirac delta function and $H_{s}$ is the source height.

$K_{z}^{n}(z)$ and $\beta_{z}^{n}(z)$ depend only on $z$ and are assumed to be averaged values. The stepwise approximation is applied to Eq. 4 by discretization of the height, $h$, into sub-layers in such a manner that inside each sub-layer, average values for $K_{z}^{n}$ and $\beta_{z}^{n}$ can be obtained. At this point, it is important to note that this procedure transforms the domain of problem Eq. 4 into a multi-layered block in the $z$ direction. It is also important to note that the stepwise approximation of a continuous function converges to the continuous function when the stepwise of the approximation goes to zero. Furthermore, this approach is quite general because it can be applied when these parameters represent an arbitrary continuous function of $z$. Note that $\beta_{z}^{n}$ and $K_{z}^{n}$ are constant in each sub-layer, but the concentration still varies with $z$ inside each layer.

To solve Eq. 4, we apply a Laplace transform of $t$. It is now possible to present problem Eq. 4 as a set of diffusive problems with constant parameters, which for a generic sub-layer is given by:

$$
\begin{aligned}
& \frac{d^{2} \hat{c}_{n}(z, p)}{d z^{2}}+\left(\frac{w_{s}+w_{s} p \tau-p \beta_{z}^{n}}{w_{s} \beta_{z}^{n}+K_{z}^{n}}\right) \frac{d \hat{c}_{n}(z, p)}{d z}-\left(\frac{p+p^{2} \tau}{w_{s} \beta_{z}^{n}+K_{z}^{n}}\right) \hat{c}_{n}(z, p)= \\
& -\left(\frac{1+p \tau}{w_{s} \beta_{z}^{n}+K_{z}^{n}}\right) Q \delta\left(z-H_{s}\right)
\end{aligned}
$$

for $n=1: N L$, where $N L$ denotes the number of sub-layers and $\hat{c}_{n}$ the concentration at the $\mathrm{n}^{\text {th }}$ sub-layer based on the Laplace Transform of the concentration over time $(t)$ (i.e., $\hat{c}(z, p)=L\{c(z, t) ; t \rightarrow p\})$.

The solution is: 


$$
\hat{c}_{n}(z, p)=A_{n} e^{m_{1} z}+B_{n} e^{m_{2} z}+Q J_{n}\left(e^{m_{2}\left(z-H_{s}\right)}-e^{m_{1}\left(z-H_{s}\right)}\right)
$$

where

$$
\begin{gathered}
m_{1}=-\frac{1}{2}\left(\frac{w_{s}+w_{s} p \tau-p \beta_{z}^{n}}{w_{s} \beta_{z}^{n}+K_{z}^{n}}\right)+\frac{1}{2} \sqrt{\left(\frac{w_{s}+w_{s} p \tau-p \beta_{z}^{n}}{w_{s} \beta_{z}^{n}+K_{z}^{n}}\right)^{2}+4\left(\frac{p+p^{2} \tau}{w_{s} \beta_{z}^{n}+K_{z}^{n}}\right)} \\
m_{2}=-\frac{1}{2}\left(\frac{w_{s}+w_{s} p \tau-p \beta_{z}^{n}}{w_{s} \beta_{z}^{n}+K_{z}^{n}}\right)-\frac{1}{2} \sqrt{\left(\frac{w_{s}+w_{s} p \tau-p \beta_{z}^{n}}{w_{s} \beta_{z}^{n}+K_{z}^{n}}\right)^{2}+4\left(\frac{p+p^{2} \tau}{w_{s} \beta_{z}^{n}+K_{z}^{n}}\right)} \\
J_{n}=\left(\frac{1+p \tau}{w_{s} \beta_{z}^{n}+K_{z}^{n}}\right) / \sqrt{\left(\frac{w_{s}+w_{s} p \tau-p \beta_{z}^{n}}{w_{s} \beta_{z}^{n}+K_{z}^{n}}\right)^{2}+4\left(\frac{p+p^{2} \tau}{w_{s} \beta_{z}^{n}+K_{z}^{n}}\right)}
\end{gathered}
$$

For a more detailed discussion of how Eqs. 5 and 6 are obtained using the ADMM method, see the works of Moreira. ${ }^{23,24}$

The solution with non-Fickian closure is more general because setting $\tau=0$ and $\beta_{z}^{n}=0$ yields the solution to the problem with Fickian closure.
Applying the initial and boundary conditions, one obtains a linear system for the integration constants $\left(A_{n}\right.$ and $\left.B_{n}\right)$. Then, the concentration is obtained by numerically inverting the transformed concentration $\hat{c}$. Finally, a robust inversion method is applied based on the Fixed Talbot (FT) algorithm, ${ }^{25,26}$ yielding the following concentration:

$$
c_{n}(z, t)=\frac{r}{M}\left[\frac{1}{2} \hat{c}_{n}(z, p) e^{r t}+\sum_{k=1}^{M-1} \operatorname{Re}\left[e^{t S\left(\theta_{k}\right)} \hat{c}_{n}\left(z, s\left(\theta_{k}\right)\right)\left(1+i \tau\left(\theta_{k}\right)\right)\right]\right]
$$

where

$$
\begin{gathered}
s\left(\theta_{k}\right)=r \theta(\cot \theta+i), \quad-\pi<\theta<+\pi \\
\tau\left(\theta_{k}\right)=\theta_{k}+\left(\theta_{k} \cot \theta_{k}-1\right) \cot \theta_{k} \\
\theta_{k}=\frac{k \pi}{M}
\end{gathered}
$$


and $r$ is a parameter based on numerical experiments. The FT method has only one free parameter: $M$, which is the number of terms in the summation. The accuracy of the algorithm increases as $M$ increases.

This turbulent parameterization represents a fundamental aspect of pollutant dispersion modeling. The classical statistical diffusion theory, observed spectral properties and observed characteristics of energy containing eddies are used to estimate the turbulent parameters in Eq. $7^{27-29}$ The formula utilized are presented in the Appendix.

\section{Numerical results}

In this section, we report the numerical results attained for the solution presented in the previous section. Simulations were conducted using the following conditions: $h$ $=1000 \mathrm{~m}$ and $w_{*}=2 \mathrm{~m} / \mathrm{s} \quad\left(w_{*}\right.$ is the convective velocity).

Vertical concentration profiles are presented in Figure 1. The simulations for this case used $w_{s}=0, v_{d}=0, \tau=0$ and $S_{k}=0$. Nondimensional concentration $C^{*}(\mathrm{ch} / Q)$ profiles are predicted to approach uniformity throughout the $1000 \mathrm{~m}$ boundary layer within $t^{*}=2\left(t^{*}=t w_{*} / h\right)$.

Figure 2 shows the effect of non-local transport for the nondimensional source height $H_{s} / h=0.1$ on the nondimensional ground-level concentration $C^{*}(c h / Q)$ as a function of the nondimensional time $t^{*}$ ( $\left.t w_{*} / h\right)$, as based on specific skewness values ( $S_{k}=0 ; S_{k}=0.5 ; S_{k}=-0.5$ ). It is possible to verify that the maximum concentration peak quantitatively varies.

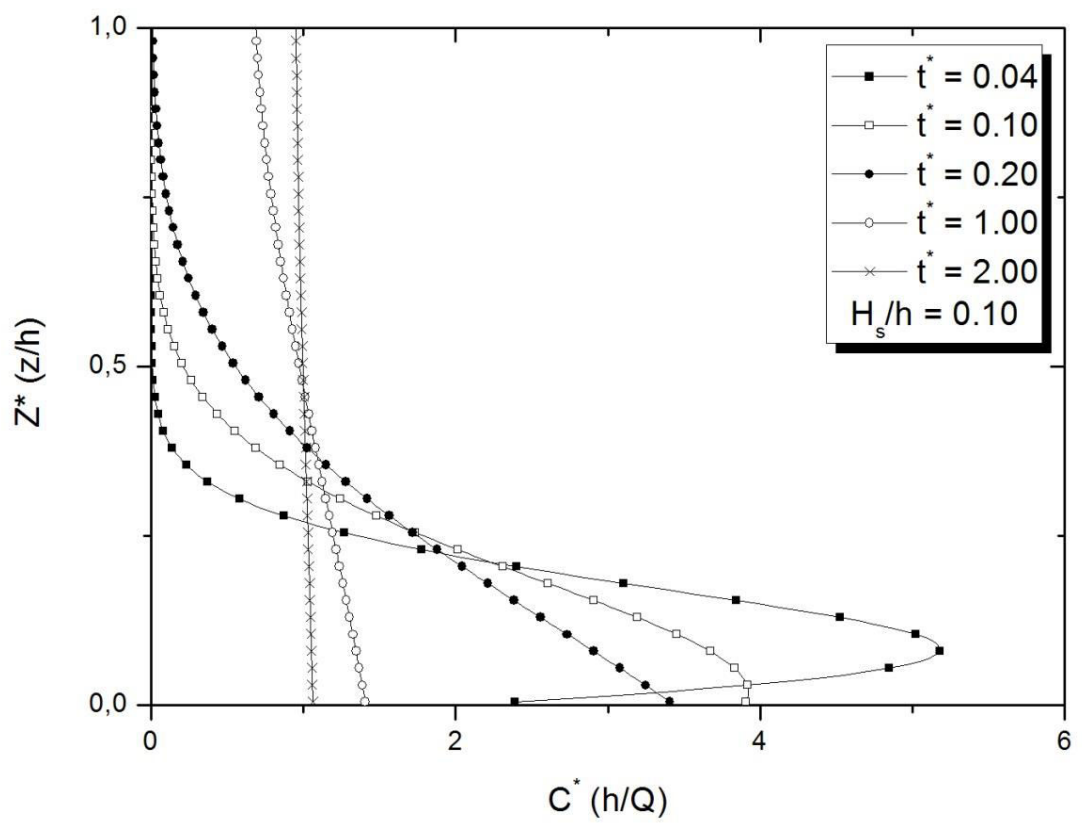

Figure 1. Nondimensional concentration profiles as a function of nondimensional times $\left(t^{*}=\right.$ $0.04,0.10,0.20,1.0$ and 2.0 ) 


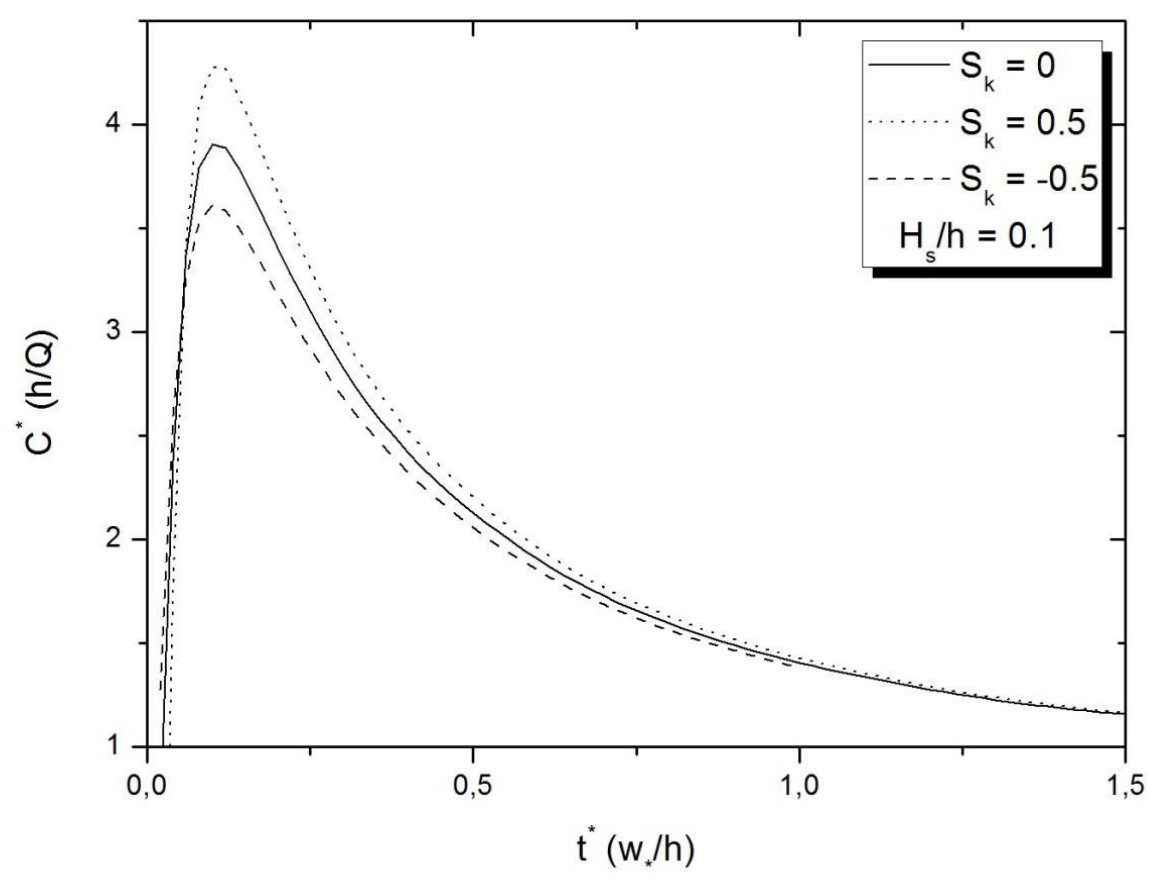

Figure 2. Nondimensional ground-level concentration $C^{*}(\operatorname{ch} / Q)$ as a function of the nondimensional time, $t^{*}\left(t w_{*} / h\right)$, for nondimensional source height $H_{s} / h=0.1$ based on specific skewness values ( $S_{k}=0 ; S_{k}=0.5 ; S_{k}=-0.5$ )

To illustrate the influence of skewness on the turbulent flow, we display numerical results, for the nondimensional concentration as a function of nondimensional time in Figure 3. We also illustrate concentration isolines for different skewness values (Figure 3(a) $S_{k}=0$; Figure 3(b) $\left.S_{k}=0.5 ; H_{s} / h=0.25\right)$. These simulations used $v_{d}=0$. As expected, the pollutant descends and impinges on the surface for the positive value of $S_{k}$, which is a result of the prevalence of downdrafts.
Figure 4 shows the effect of the boundary condition (4b) on the turbulent deposition from the source height to the ground. This figure compares the vertical profile of the nondimensional concentration with and without turbulent deposition for $H_{s} / h=$ 0.05 and $t^{*}=0.04$. A pollutant with no deposition velocity is reflected back into the atmosphere. By contrast, a pollutant with a deposition velocity $\left(v_{d}=0.05 \mathrm{~m} / \mathrm{s}\right)$ undergoes substantial depositional losses, thereby reducing airborne concentrations. 

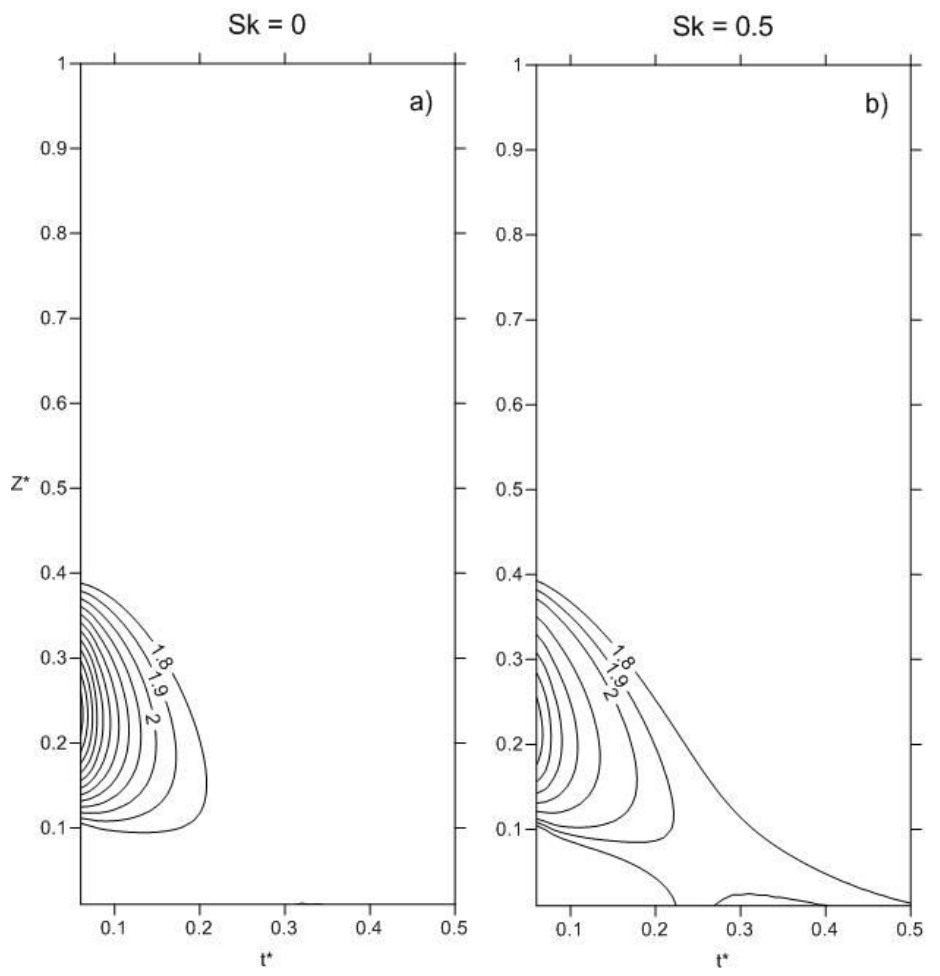

Figure 3. Isolines of the nondimensional concentration $C^{*}\left(c h / Q ; z^{*}=z / h ; t^{*}=t w^{*} / h\right)$ predicted for different skewness values: (a) $S_{k}=0$ and (b) $0.5 ; H_{s} / h=0.25, \tau=1 \mathrm{~s}$ and $w_{s}=0.05 \mathrm{~m} / \mathrm{s}$

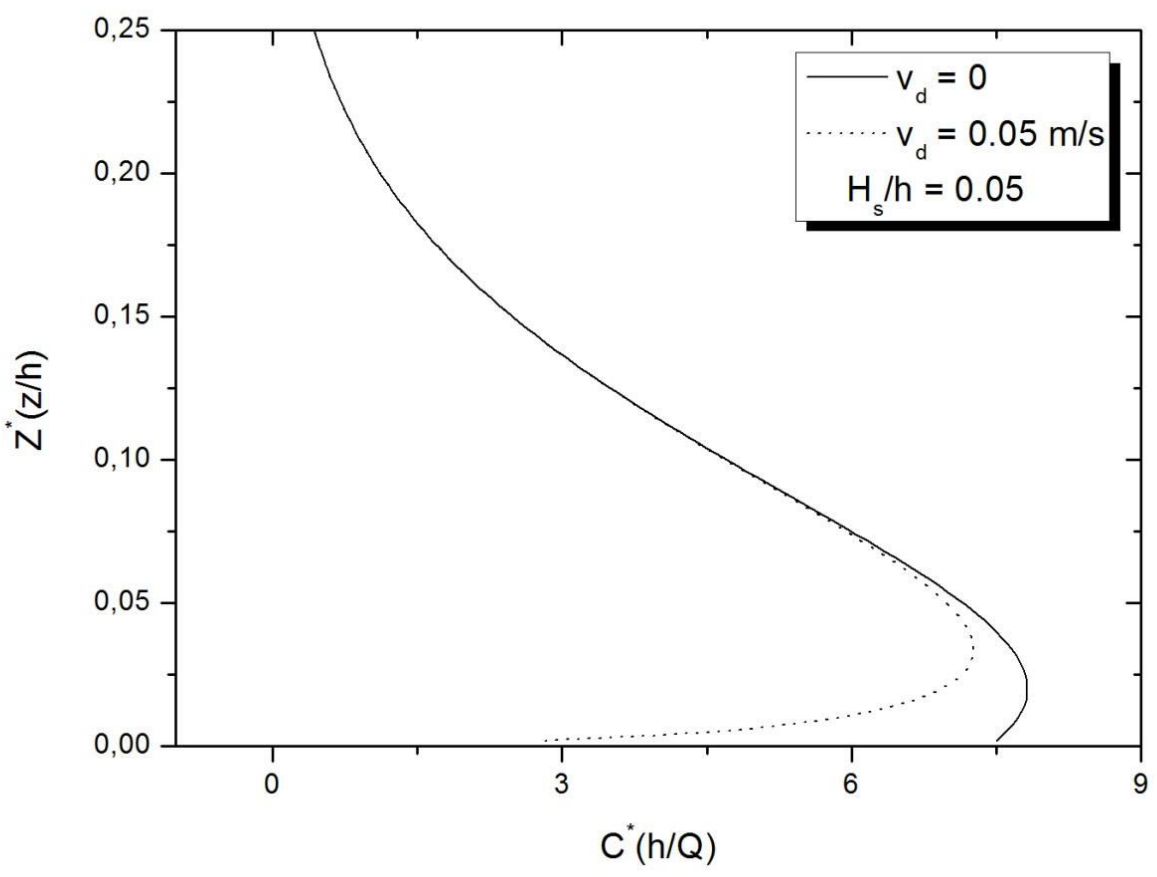

Figure 4. Vertical profile of the nondimensional concentration with deposition (continuous line) and non-deposition (dotted line) at $H_{s} / h=0.05$ and $t^{*}=0.04$ 
Figure 5 shows the variations of nondimensional ground-level concentrations as a function of nondimensional time $t^{*}$ using various settling velocities and source heights of $H_{s} / h=0.25$ and $H_{s} / h=0.5$. Increasing the settling velocity increases the peak concentration, and when the settling velocity exceeds the deposition velocity, ground-level concentrations exceed those without deposition.

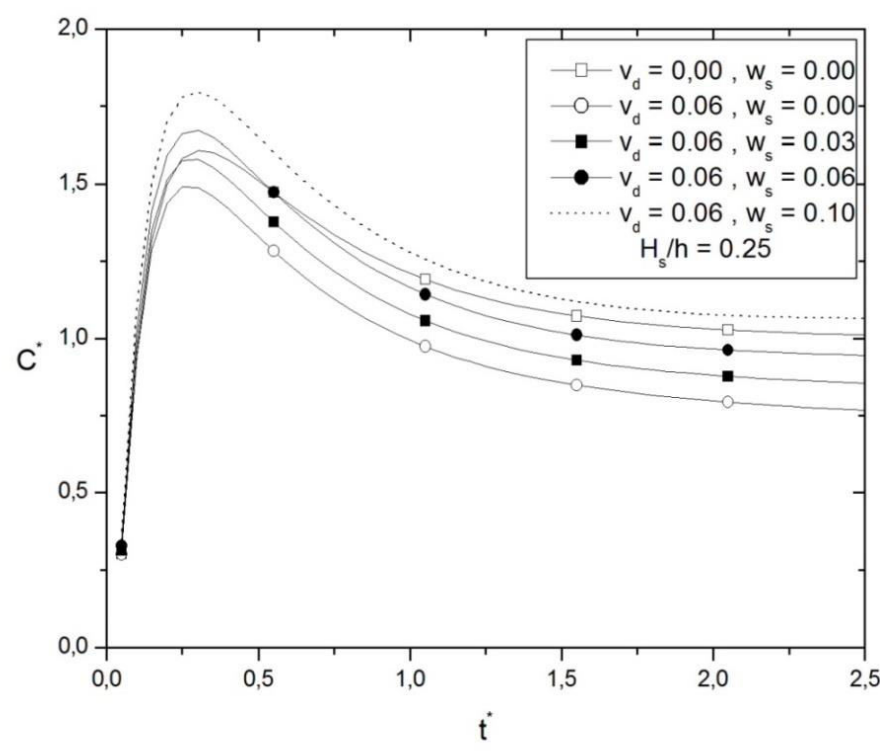

(a)

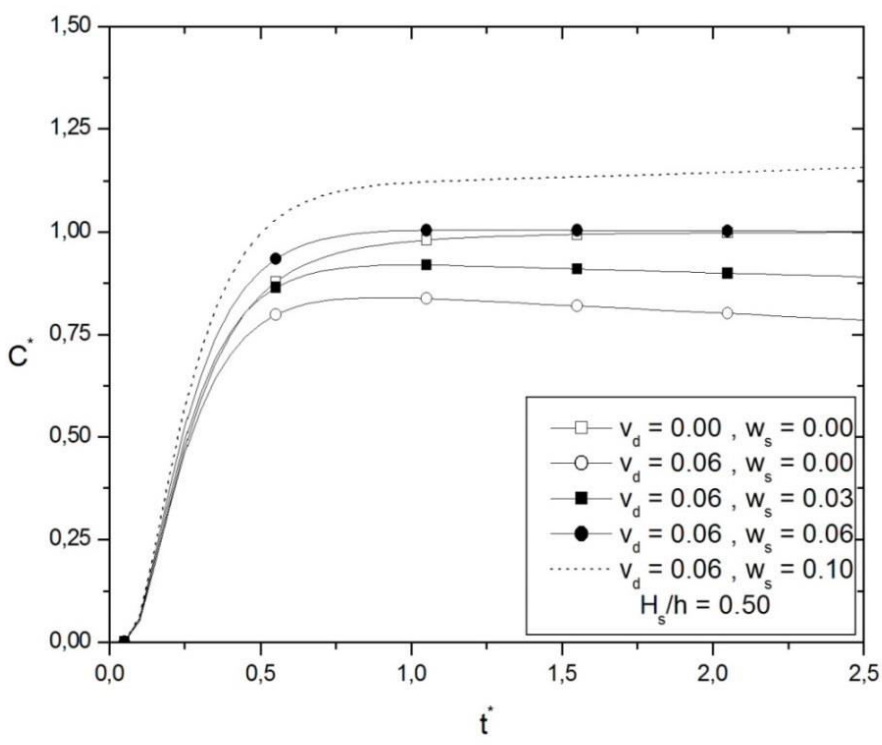

(b)

Figure 5. Nondimensional ground-level concentrations as a function of nondimensional time $t^{*}$ using different settling velocities based on source height: a) $H_{s} / h=0.25$ and b) $H_{s} / h=0.5$ 
To better illustrate this, concentration isolines for a source at $H_{s} / h=0.25$ are presented in Figure 6 , where settling velocities are lower or higher than that of deposition. Note that in the second case, a concentration rebound is observed from the ground upward. The concentration flow at ground level is actually greater than the underlying ground can absorb.

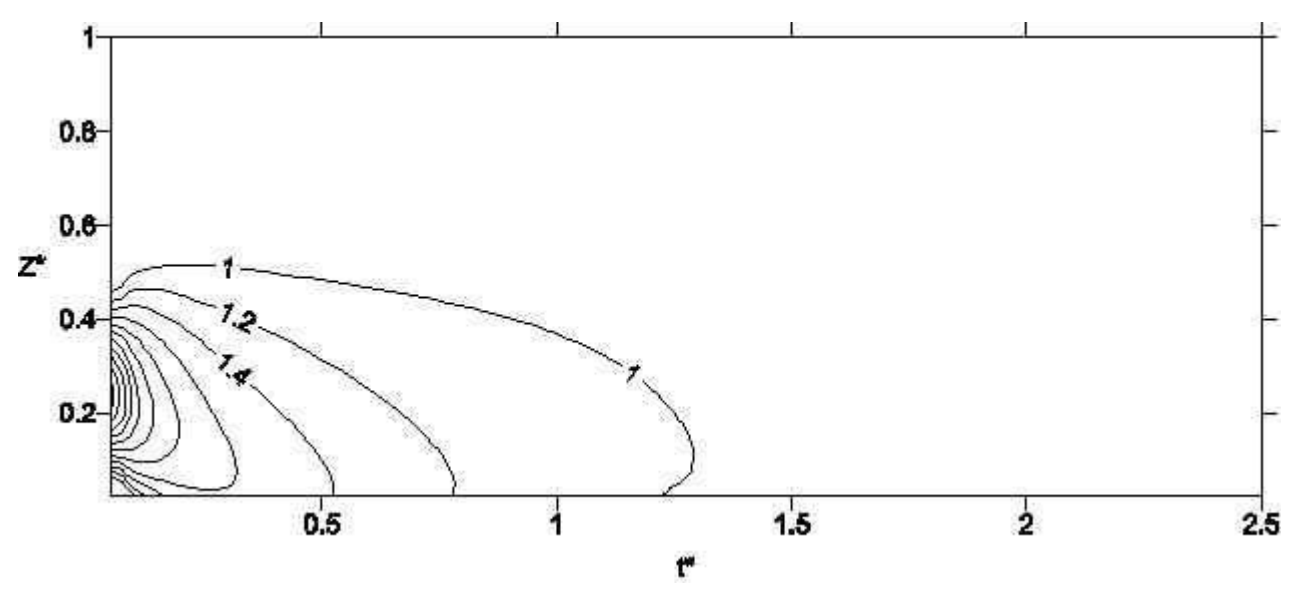

(a)

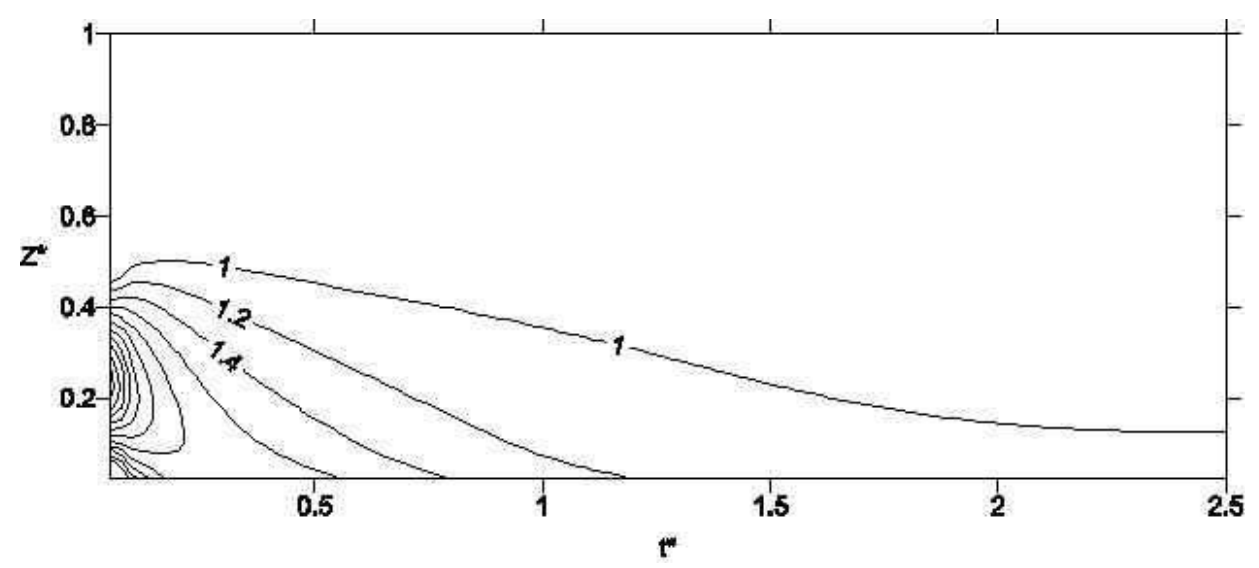

(b)

Figure 6. Concentration isolines for a source at $H_{s} / h=0.25$ based on the conditions for: a) $v_{d}=0.06$ and $w_{s}=0.03 \mathrm{~m} / \mathrm{s}$ and b) $v_{d}=0.06$ and $w_{s}=0.1 \mathrm{~m} / \mathrm{s}$

\section{Conclusions}

We presented an analytical solution of the advection-diffusion equation considering a vertically inhomogeneous $A B L$. Note that in this one dimensional approach, no approximation is made in the solution derivation, except for the stepwise approximations of the wind and eddy diffusivity vertical profiles.

Through numerical simulations based on the ADMM approach, we analyzed the influence of the countergradient term, dry deposition to the ground and explicit gravitational settling. Furthermore, realistic turbulent parameterizations based on observations were used during pollutant 
vertical dispersion simulations from a continuous source.

The results indicate that the non-local closure is significant and affects the dispersion calculations. The countergradient term alters the peak concentration value. This is an important result because the determination of the maximum ground-level concentration is one of the most important aspects of air quality control.

The introduction of the dry deposition consistently changes ground level concentrations, as well as the vertical concentration profiles near the ground. The settling velocity alters the concentration profiles throughout the entire $A B L$, but if greater than the deposition velocity, it causes pollutant concentration accumulation in the ground.

Moreover, the simulations indicate that the gravitational settling and local dry deposition can significantly influence air pollution concentration distributions and maximum concentrations near the ground. This study also highlights the use of analytical solutions as technical tools for studying and understanding transport and diffusion in the atmosphere.

\section{Appendix}

Turbulent parameterizations

The general expressions for $\sigma_{w}, K_{z}$ and $T_{L_{w}}$ are given by the following:

a) Standard deviation of the vertical turbulent velocity:

$$
\sigma_{w}=\left[\frac{1.06 c_{w} \psi^{2 / 3}}{\left(f_{m}^{*}\right)_{w}^{2 / 3}}\left(\frac{z}{h}\right)^{2 / 3} w_{*}^{2}\right]^{1 / 2}, \quad\left(c_{w}=4 / 3\right)
$$

b) Vertical eddy diffusivity:

$$
K_{z}=\frac{0.55}{4} \frac{\sigma_{w} z}{\left(f_{m}^{*}\right)_{w}}
$$

c) Vertical Lagrangian time scale:

$$
T_{L_{w}}=\frac{0.55}{4} \frac{1}{\sigma_{w}} \frac{z}{\left(f_{m}^{*}\right)_{w}}
$$

The nondimensional molecular dissipation rate function is given by:

$$
\psi^{1 / 3}=\left[\left(1-\frac{z}{z_{i}}\right)^{2}\left(\frac{z}{-L}\right)^{-2 / 3}+0.75\right]^{1 / 2}
$$

where $L$ is the Monin-Obukhov length.

The reduced frequency of the convective spectral peak is:

$$
\left(f_{m}^{*}\right)_{w}=\frac{z}{\left(\lambda_{m}\right)_{w}}
$$

and the vertical wavelength at the spectral peak is: 


$$
\left(\lambda_{m}\right)_{w}=1.8 h\left[1-\exp \left(\frac{-4 z}{h}\right)-0.0003 \exp \left(\frac{8 z}{h}\right)\right]
$$

where $w_{*}$ is the convective velocity.

\section{References}

${ }^{1}$ Chamberlain, A. C. Aspects of travel and deposition of aerosol and vapour clouds. UKAEA Rep. AERE-HP/R-1261, Harwell, Berkshire, United Kingdom, 1953, 35.

2 Overcamp, T. J. A general Gaussian diffusion-deposition model for elevated point sources. Journal of Applied Meteorology and Climatology 1976, 15, 1167. [CrossRef]

${ }^{3}$ Horst, T. W. A surface depletion model for deposition from a Gaussian plume. Atmospheric Environment 1967, 11, 41. [CrossRef]

${ }^{4}$ Horst, T. W. The modification of plume models to account for dry deposition. Boundary-Layer Meteorology 1984, 30, 413. [CrossRef]

${ }^{5}$ Smith, F. B. The problem of deposition in atmospheric diffusion of particulate matter. Journal of the Atmospheric Sciences 1962, 19, 429. [CrossRef]

${ }^{6}$ Ermak, D. L. An analytical model for air pollutant transport and deposition from a point source. Atmospheric Environment 1967, 11, 231. [CrossRef]

${ }^{7}$ Rao, K. S. Analytical solutions of a gradienttransfer model for plume deposition and sedimentation. NOAA Tech. Memo. ERL ARL109 Air Resources Laboratories, 1981, 75.

${ }^{8}$ Tsuang, B. J. Quantification on the source/receptor relationship of primari pollutants and secondary aerosols by a Gaussian plume trajectory model: Part I theory. Atmospheric Environment 2003, 37, 3981. [CrossRef]

${ }^{9}$ Deardoff, J. W.; Willis, G. E. A parameterization of diffusion into the mixed layer. Journal of Applied Meteorology and Climatology 1975, 14, 1451. [CrossRef]

${ }^{10}$ Deardoff, J. W. The countergradient heat flux in the lower atmosphere and in the laboratory. Journal of the Atmospheric Sciences 1966, 23, 503. [CrossRef]

${ }^{11}$ Deardoff, J. W. Numerical investigation of neutral and unstable planetary boundary layers. Journal of the Atmospheric Sciences 1972, 29, 91. [CrossRef]

${ }^{12}$ Wyngaard, J. C.; Brost, R. A. Top-down botton-up diffusion of a scalar in the convective boundary layer. Journal of the Atmospheric Sciences 1984, 41, 102. [CrossRef]

${ }^{13}$ Holtslag, A.; Moeng, C. H. Eddy diffusivity and countergradient transport in the convective atmospheric boundary layer. Journal of the Atmospheric Sciences 1991, 48, 1690. [CrossRef]

${ }^{14}$ Wyngaard, J. C.; Weil, J. C. Transport asymmetry in skewed turbulence. Physics of Fluids 1991, A3, 155. [CrossRef]

${ }^{15}$ Robson, R. E.; Mayocchi, C. L. A simple model of countergradient flow. Physics of Fluids 1994, 6, 1952. [CrossRef]

${ }^{16}$ Zilitinkevich, S.; Gryanik, V. M.; Lykossov, V. N.; Mironov, D. V. Third-order transport and nonlocal turbulence closures for convective boundary layers. Journal of the Atmospheric Sciences 1999, 56, 3463. [CrossRef]

${ }^{17}$ van Dop, H.; Verver, G. Countergradient transport revisited. Journal of the Atmospheric Sciences 2001, 58, 2240. [CrossRef]

${ }^{18}$ Hoppel, W. A.; Caffrey, P. F. Turbulent diffusion with gravitational settling in a capped atmospheric boundary layer - An analytical solution. Atmospheric Environment 2011, 45, 6257. [CrossRef]

${ }^{19}$ Nieuwstadt, F. T. M. An analytical solution of the time-dependent, one-dimensional diffusion equation in the atmospheric boundary layer. Atmospheric Environment 1980, 14, 1361. [CrossRef]

${ }^{20}$ Rounds W. Solutions of the twodimensional diffusion equation. Eos, Transactions American Geophysical Union 1955, 36, 395. [CrossRef] 
${ }^{21}$ Calder, K. L. Atmospheric diffusion of particulate material considered as a boundary value problem. Journal of Meteoroly 1961, 18, 413. [CrossRef]

${ }^{22}$ Pasquill, F.; Smith, F. B. Atmospheric Diffusion, John Wiley and Sons: Chichester, 1983.

${ }^{23}$ Moreira, D. M.; Rizza, U.; Vilhena, M. T. Goulart, A. G. Semi-analytical model for pollution dispersion in the planetary boundary layer. Atmospheric Environment 2005, 39, 2689. [CrossRef]

${ }^{24}$ Moreira, D. M.; Moraes, A. C.; Goulart, A. G.; Albuquerque, T. T. A contribution to solve the atmospheric diffusion equation with eddy diffusivity depending on source distance. Atmospheric Environment 2014, 83, 254. [CrossRef]

${ }^{25}$ Talbot, A. The accurate numerical inversion of Laplace transforms. IMA Journal of Applied Mathematics 1979, 23, 97. [CrossRef]
${ }^{26}$ Abate, J.; Valkó, P. P. Multi-precision Laplace transform inversion. International Journal for Numerical Methods in Engineering 2004, 60, 979. [CrossRef]

${ }^{27}$ Degrazia, G. A.; Campos Velho, H. F.; Carvalho, J. C. Nonlocal exchange coefficients for the convective boundary layer derived from spectral properties. Beiträge zur Physic der Atmosphäre 1997, 70, 57.

${ }^{28}$ Degrazia, G. A.; Anfossi, D.; Carvalho, J. C.; Mangia, C.; Tirabassi, T.; Campos Velho; H. F. Turbulence parameterisation for PBL dispersion models in all stability conditions. Atmospheric Environment 2000, 34, 3575. [CrossRef]

${ }^{29}$ Degrazia, G. A.; Moreira, D. M.; Vilhena, M. $T$. Derivation of an eddy diffusivity depending on source distance for vertically inhomogeneous turbulence in a convective boundary layer. Journal of Applied Meteorology and Climatology 2001, 40, 1233. [CrossRef] 